\title{
ASSOCIATION OF MAST CELLS IN OCCLUSIVE VASCULAR DISEASE IN IDIOPATHIC OLIGOSPERMIA
}

\author{
S. Siew*, P. Troen**, H.R. Nankin** \\ *Division of Human Pathology, College of Osteopathic Medicine, Michigan State University, East \\ Lansing, MI 48824 \\ **Department of Medicine, University of Pittsburgh, Pittsburgh, PA 15206
}

In an investigation of idiopathic oligospermia, we examined, by means of transmission electron microscopy 36 testicular biopsies from 20 patients. Control material consisted of 16 biopsies from 8 orchiectomy cases. Oligospermia was defined as less than $40 \times 10^{6} / \mathrm{ml}$ spermatozoa; three of the cases were just above $20 \times 10^{6} / \mathrm{ml}$. There were no significant abnormalities in the relevant cytogenetic, biochemical and endocrine profiles.

Preliminary findings in the first 12 biopsies from 6 patients, have been documented. (Refs. 1, 2, 3). These findings were confirmed and extended in the present investigation. Transmission electron microscopy of the seminiferous tubules showed the presence of increased reduplication and infolding of the lamina propria. There was parenchymatous degeneration of the germinal epithelium, maturation arrest with diminution of mature germ cells and an increase in abnormal forms of spermatids. Sertoli cells were prominent and there was one case of "Sertoli cell only."

The lamina propria was increased in thickness, due mostly to an increase in collagen. There were, also, some fine fibrils and basement membrane-like material, in it. The interstitial tissue was increased in amount and it was more fibrous. Leydig cells showed the presence of myelin figures. Reinke crystals were present in a half of the cases. Fibroblasts and occasional smooth muscle cells were noted in the interstitial tissue. The striking feature was the vascular lesion. There was enlargement of the endothelial cells. In some cases this was due to swelling and loosening of the cytoplasm, but, in most instances, there was a well marked increase in the size of the nuclei, with progressive encroachment upon the lumen, which was virtually obliterated, in some cases. The blood vessels were encompassed by an increased amount of perivascular supporting tissue. This ranged from a loose fibrillar matrix to collagen fibers, and, it varied in degree, with some of the blood vessels being embedded in dense fibrous tissue.

An interesting finding was the presence of mast cells, in close proximity to the blood vessels (Fig. 1). This raises the possibility that the mast cells may contribute to the pathogenesis of the obliterative vascular lesions and the interstitial fibrosis. Normal vascular tone and connective tissue architecture are regulated by the interaction of endothelial cells, mast cells and fibroblasts. Mast cells release heparin, which binds to endothelial cells and is internalized by them, causing the release of endothelial derived growth factor. Endothelial derived growth factor is a mediator of endothelial cell mitogenesis and it stimulates fibroblasts. In addition, platelets may play a role, as they will adhere to dysfunctional endothelium and will release platelet derived growth factor and transforming growth factor beta. One vessel was completely occluded by a platelet thrombus. It is suggested that the deprivation of blood supply to the seminiferous tubule by the occlusive vascular lesion impairs spermatogenesis and contributes to the oligospermia.

References:

[1] S. Siew et. al., $34^{\text {th }}$ Ann. Proc. Electron Microscopy Soc. Amer. 156.

[2] S. Siew et. al., "Ultrastructural Study of Human Testicular Biopsies in Infertility "in" Male Reproductive System", 79-99, Masson Publishing USA, Inc, NY 1977.

[3] S. Siew et. al., "Ultrastructure of Testicular Biopsies from Infertile Men "in" The Testis in Normal and Infertile Men”, 137-152, Raven Press, NY, 1977. 


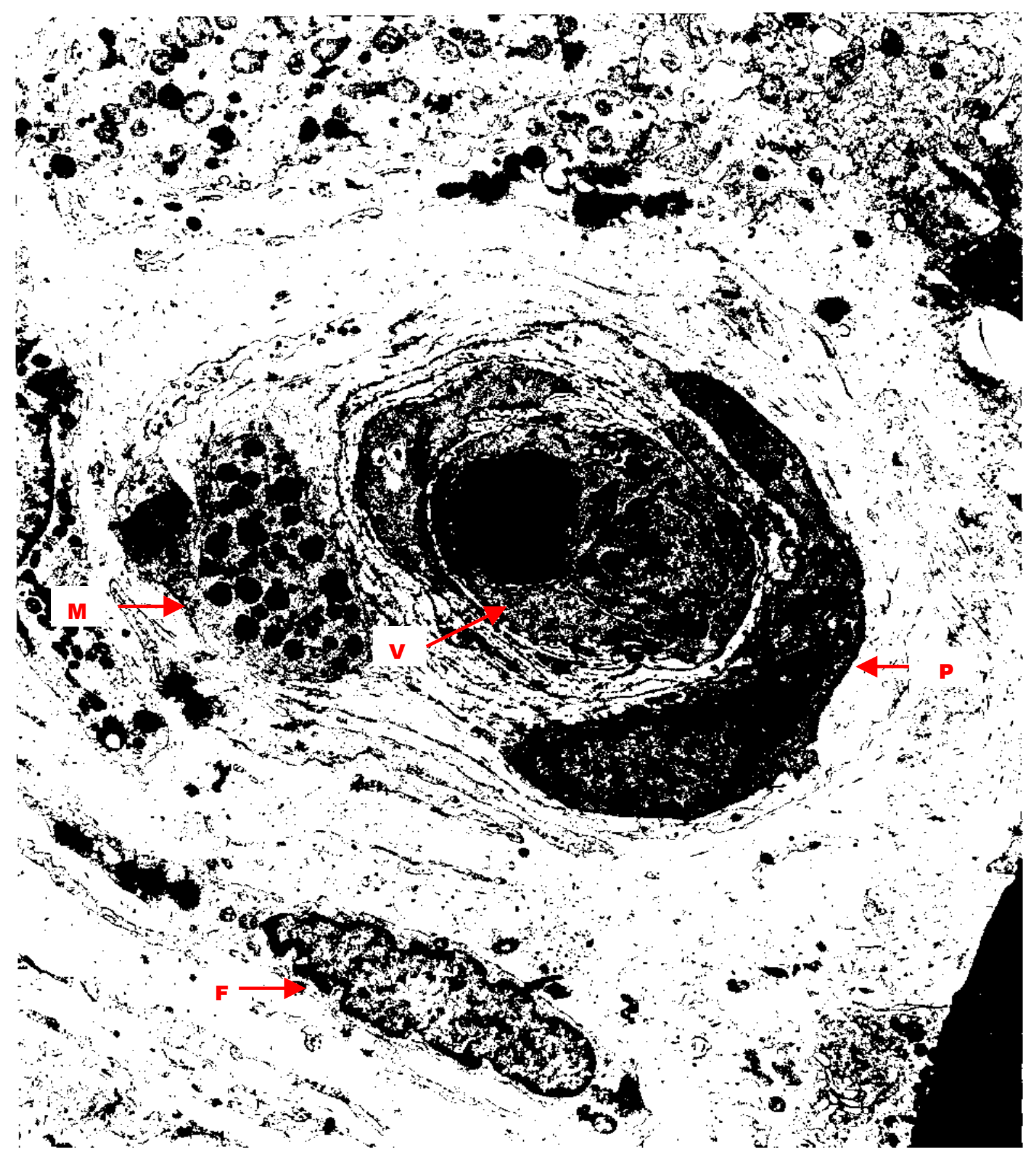

FIG 1. TEM Mast cell (M) in close proximity to narrowed blood vessel (V) Note increase infibrous tissue, concentrated around the blood vessel. (F) Fibroblast (P) Pericyte (x7500). 